\title{
Genetic control of chicken heterophil function in advanced intercross lines: associations with novel and with known Salmonella resistance loci and a likely mechanism for cell death in extracellular trap production
}

\author{
Sarah B. Redmond • Phongsakorn Chuammitri • \\ Claire B. Andreasen • Dušan Palić • Susan J. Lamont
}

Received: 7 January 2011 / Accepted: 8 March 2011 /Published online: 1 April 2011

(C) The Author(s) 2011. This article is published with open access at Springerlink.com

\begin{abstract}
Heterophils, the avian polymorphonuclear leukocyte and the counterpart of mammalian neutrophils, generate the primary innate response to pathogens in chickens. Heterophil performance against pathogens is associated with host disease resistance, and heterophil gene expression and function are under genetic control. To characterize the genomic basis of heterophil function, heterophils from $\mathrm{F}_{13}$ advanced intercross chicken lines (broiler $\times$ Leghorn and broiler $\times$ Fayoumi) were assayed for phagocytosis and killing of Salmonella enteritidis, oxidative burst, and extracellular trap production. A whole-genome association analysis of single nucleotide polymorphisms at 57,636 loci identified genomic locations controlling these functional phenotypes. Genomic analysis revealed a significant association of extracellular trap production with the SAL1 locus and the SLC11A1 gene, which have both been previously associated with resistance to $S$. enteritidis. Fine mapping supports SIVA1 as a candidate gene controlling SAL1-
\end{abstract}

S. B. Redmond $\cdot$ S. J. Lamont $(\bowtie)$

Department of Animal Science, Iowa State University, Ames, IA 50011, USA

e-mail: sjlamont@iastate.edu

P. Chuammitri

Department of Veterinary Microbiology and Preventative

Medicine, Iowa State University,

Ames, IA 50011, USA

C. B. Andreasen

Department of Veterinary Pathology, Iowa State University,

Ames, IA 50011, USA

D. Palić

Department of Biomedical Sciences, Iowa State University,

Ames, IA 50011, USA mediated resistance and indicates that the proposed celldeath mechanism associated with extracellular trap production, ETosis, likely functions through the CD27/Siva-1mediated apoptotic pathway. The SLC11A1 gene was also associated with phagocytosis of $S$. enteritidis, suggesting that the Slc1lal protein may play an additional role in immune response beyond depleting metal ions to inhibit intracellular bacterial growth. A region of chromosome 6 with no characterized genes was also associated with extracellular trap production. Further characterization of these novel genes in chickens and other species is needed to understand their role in polymorphonuclear leukocyte function and host resistance to disease.

Keywords Heterophil · Chicken · Extracellular trap · Salmonella resistance . Cell death
Abbreviations
PMN Polymorphonuclear leukocyte
HET Heterophil extracellular trap
SNP Single nucleotide polymorphism
AIL Advanced intercross line
GO Gene ontology

\section{Introduction}

Polymorphonuclear leukocytes (PMN) are an essential component of the innate immune system, rapidly detecting and killing pathogens and signaling to direct other immune response mechanisms. Heterophils are the avian PMN, which unlike mammalian neutrophils have low capacity for producing reactive oxygen species because of the absence 
of myeloperoxidase in heterophil granules (Brune et al. 1972; Harmon 1998). Like neutrophils, heterophils perform essential functions in the early response to pathogens, and the rapid activation and chemotaxis of heterophils allows these responses to be mounted quickly (Kogut et al. 1995). Detection of bacterial molecules through Toll-like receptors stimulates heterophil phagocytosis and oxidative burst (Kogut et al. 2001; Farnell et al. 2003) and induces expression of pro-inflammatory cytokines (Kogut et al. 2005). Heterophil granules contain antimicrobial substances that can be released through degranulation to kill phagocytized bacteria (He et al. 2005) or extruded with chromatin as the recently discovered heterophil extracellular traps (HETs, Chuammitri et al. 2009). The genomic regulation of these processes has not been interrogated in PMN, and the control of HET production is of particular interest as an alternative mechanism of programmed cell death (Fuchs et al. 2007).

In addition to furthering the understanding of the mechanisms by which PMN combat pathogens, the study of chicken heterophils is of interest to benefit human and animal health. Variability in heterophil gene expression and function is associated with resistance to pathogens in chickens. Of particular interest in poultry is resistance to Salmonella enteritidis, a zoonotic pathogen which is transmitted through consumption of contaminated eggs and is a major cause of food-borne illness in humans. Genomic regions associated with resistance to Salmonella challenge have been identified based on bacterial burden in different chicken populations (Lamont et al. 2002; Fife et al. 2009, 2010). Differences in heterophil expression of proinflammatory cytokines have been correlated with resistance to S. enteritidis (Stabler et al. 1994; Swaggerty et al. 2004; Redmond et al. 2009), and phenotypic selection for heterophil expression profile has been proposed as a method to increase $S$. enteritidis resistance (Swaggerty et al. 2008). Genetically enhanced resistance through augmentation of the immune response is an alternative to the use of antibiotics in maintaining healthy food-producing animals.

Previous analyses of the broiler, Leghorn, and Fayoumi lines that are the founder lines of the advanced intercrosses used in the current study have shown among-line variation in the heterophil response to $S$. enteritidis (Redmond et al. 2009). The broiler line is typical of birds selected for commercial meat production, and gene expression in broiler immune tissues varies little in response to $S$. enteritidis or dietary immunomodulators (Redmond et al. 2009, 2010). The Leghorn line has been selected for high egg production and alters expression of immune response genes under $S$. enteritidis challenge (Cheeseman et al. 2007) and immunomodulatory diet (Redmond et al. 2010). The Fayoumi line is an indigenous line, not selected for any commercial traits, which originated in Egypt. Birds from the Fayoumi line have a strong heterophil response to $S$. enteritidis bacteria, which induces cytokine gene expression and phagocytosis at higher levels than in the broiler or Leghorn lines (Redmond et al. 2009). The divergent selection histories and phenotypes of these founder lines facilitate the detection of markers in the intercross offspring associated with founder line alleles that significantly alter heterophil phenotype. To identify the genetic basis of the variation in heterophil response, isolated heterophils of individuals from the $F_{13}$ generation of two advanced intercross lines, broiler $\times$ Leghorn $(\mathrm{Br} \times \mathrm{Leg})$ and broiler $\times$ Fayoumi $(\mathrm{Br} \times$ Fay), were evaluated for functional resistance traits: phagocytosis and killing of $S$. enteritidis bacteria, oxidative burst, and production of heterophil extracellular traps (HETs). These heterophil phenotypes were associated with specific chromosomal regions using a high-density genome-wide scan of single nucleotide polymorphisms (SNPs). Pathway analysis of identified genes was used to further elucidate the primary mechanisms active in each functional phenotype.

\section{Materials and methods}

\section{Experimental animals}

Two intercross lines were generated by breeding a single outbred broiler (meat-type) male (Kaiser et al. 1998) to highly inbred Leghorn and Fayoumi females $(F>0.99$; Zhou and Lamont 1999), and intermating the offspring within each intercross line. Birds from the $\mathrm{F}_{13}$ generation of each advanced intercross line (AIL) were selected randomly from three hatch groups to provide replication for this experiment, with a total of 152 birds from the broiler $\times$ Leghorn AIL and 189 from the broiler $\times$ Fayoumi AIL. All chicks were tagged at hatch to identify pedigree. Chicks were separated by age and reared in floor pens at the Iowa State University Poultry Science Research and Education Center with ad libitum access to water and standard commercial feed. From 5 to 8 weeks of age, birds were fed a basal diet or a $\beta$-glucan-enhanced diet, however, diet itself and the interaction of dietary and genetic factors showed relatively little effect on the heterophil phenotypes; therefore, diet as a main or interaction factor was not further included in the analysis. Individual body weights were measured weekly from week 5 through week 8 of age. Experimental protocols for this study were reviewed and approved by the Iowa State University Institutional Animal Care and Use Committee.

Blood collection, DNA, and heterophil isolation

At 8 weeks of age, whole venous blood was collected via syringe from each bird and mixed 9:1 $v / v$ with 10\% EDTA 
in solution (Sigma-Aldrich, St. Louis, MO). A small volume $(\sim 200 \mu \mathrm{L})$ of blood was set aside for DNA isolation. Heterophils were isolated from the remaining 15$20 \mathrm{~mL}$ as previously described (Chuammitri et al. 2009). Briefly, chicken blood was mixed with $1 \%$ methylcellulose, centrifuged $(15 \times g, 15 \mathrm{~min})$, the buffy coat was collected, placed on discontinuous density gradient (Histopaque, Sigma-Aldrich; specific gravity 1.077 over $1.119 \mathrm{~g} / \mathrm{mL}$ ), and then centrifuged $(500 \times \mathrm{g}, 30 \mathrm{~min})$. The $1.077 / 1.119 \mathrm{~g} / \mathrm{mL}$ interface and $1.119 \mathrm{~g} / \mathrm{mL}$ bands were collected, resuspended in calcium and magnesium-free Hank's balanced salt solution with fetal bovine serum, and washed $(370 \times g$, $10 \mathrm{~min}$ ). Red blood cells were lysed for $3 \mathrm{~min}$ and washed, and the final heterophil suspension $(>95 \%$ viable heterophils) was diluted to $5 \times 10^{6}$ cells $/ \mathrm{mL}$ in Hank's balanced salt solution.

\section{Heterophil phenotype evaluation}

Isolated heterophils from individual birds were assessed for phagocytosis $(n=327$ birds), bacterial killing $(n=298)$, oxidative burst $(n=331)$, and HET production capabilities $(n=308)$ using in vitro assays. All assays were conducted in duplicate, and mean values for each individual were used to represent heterophil functional phenotypes. Data set values were transformed, as needed, to fit a normal distribution $\left[(\% \text { bacterial killing })^{2}, 1 /\right.$ (oxidative burst stimulation in$\operatorname{dex})^{2}, 1 /($ HET index $\left.)\right]$, and the transformed values were used in statistical analysis. Correlation between phenotypes was assessed using Pearson's coefficient.

Phagocytosis was measured using heat-killed $S$. enteritidis bacteria labeled with SYTOX $(10 \mu \mathrm{M}$ SYTOX Green, Molecular Probes, Eugene, OR) and opsonized with 10\% chicken serum (Atlanta Biologicals, Lawrenceville, GA). Heterophils $\left(2.5 \times 10^{5}\right.$ cells $)$ were mixed with $2.5 \times 10^{6}$ CFUs S. enteritidis bacteria, centrifuged $\left(400 \times g, 5 \mathrm{~min}, 4^{\circ} \mathrm{C}\right)$ and incubated for $2 \mathrm{~h}\left(41^{\circ} \mathrm{C}\right.$ with $\left.5 \% \mathrm{CO}_{2}\right)$. Cells were fixed with $1 \%$ paraformaldehyde (Polysciences, Warrington, PA) and fluorescence of phagocytized bacteria measured via BD FACSCanto flow cytometer (BD Biosciences, San Jose, CA). Data were analyzed with FlowJo 6.0 (TreeStar, Ashland, OR) and standardized to generate mean fluorescence intensity, with non-stimulated heterophils set at a value of 100 units.

Heterophil bacterial killing was assessed against freshly prepared S. enteritidis which were opsonized with $20 \%$ chicken serum $\left(20 \mathrm{~min}, 37^{\circ} \mathrm{C}\right)$. Opsonized $S$. enteritidis pellets $\left(10^{6} \mathrm{CFUs}\right)$ and $5 \times 10^{5}$ heterophils were placed into individual microtiter plate wells, centrifuged $(400 \times g, 5 \mathrm{~min}$, $\left.4{ }^{\circ} \mathrm{C}\right)$, and incubated for $45 \min \left(41{ }^{\circ} \mathrm{C}\right.$ with $\left.5 \% \mathrm{CO}_{2}\right)$. Control wells containing only $S$. enteritidis bacteria were used to standardize the assay. Following incubation, supernatant was removed and heterophils were lysed with $120 \mu \mathrm{L}$ of deionized water for $3 \mathrm{~min}$. Following lysis,
$150 \mu \mathrm{L}$ of 2,3-bis (2-methoxy-4-nitro-5-sulfophenyl)-2Htetrazolium-5-carboxanilide solution (Sigma-Aldrich) was added to each well, plates were rocked for $1 \mathrm{~min}$, and then incubated to allow for color development $\left(41^{\circ} \mathrm{C}, 90 \mathrm{~min}\right)$. Optical density of the contents of each well was measured at $\mathrm{OD}_{450-650}$ using a microtiter plate spectrophotometer (VMax, Molecular Devices, Sunnyvale, CA). The percent killing for each sample was calculated as: \% Killing = $100-\left[\left(\mathrm{OD}_{\text {Test well }} \times 100\right) / \mathrm{OD}_{\text {Control well }}\right]$.

Heterophil generation of reactive oxygen species by oxidative burst was measured following stimulation in microtiter plates with PMA (Sigma Aldrich). Heterophils $\left(2.5 \times 10^{5}\right.$ cells $)$ were incubated with $0.1 \mu \mathrm{g} / \mathrm{mL}$ PMA and $10 \mu \mathrm{M}$ carboxy-2',7'-difluorodihydrofluorescein diacetate at $41{ }^{\circ} \mathrm{C}$ with $5 \% \mathrm{CO}_{2}$ for $2 \mathrm{~h}$. Following incubation, relative fluorescence was measured at 492/520 nm using a SpectraMAX Gemini XS plate reader (Molecular Devices). The mean relative fluorescence of non-stimulated controls was used to calculate the stimulation index for each sample: Stimulation index $=$ Relative fluorescene Stimulated $_{\text {Relative }}$ fluorescen $\mathrm{e}_{\text {Non-stimulated }}$.

Extrusion of chromatin as HETs was quantified by measuring extracellular DNA (Chuammitri et al. 2009). Heterophils $\left(2.5 \times 10^{5}\right)$ were stimulated with $0.15 \mathrm{mM}$ hydrogen peroxide (Fisher Scientific, Waltham, MA) for $2 \mathrm{~h}$ at $41^{\circ} \mathrm{C}$ with $5 \% \mathrm{CO}_{2}$. Extracellular DNA was digested with Micrococcal nuclease (MNase; $500 \mathrm{mU} / \mathrm{mL}$, Worthington Biochemical, Lakewood, NJ) for $20 \mathrm{~min}$ at $37^{\circ} \mathrm{C}$. Quant-iT PicoGreen dsDNA Reagent (Molecular Probes) was used to quantify double-stranded DNA following the manufacturer's protocol. Relative fluorescence was measured $(492-520 \mathrm{~nm})$, and HET release was calculated for each sample relative to the mean non-stimulated cell values as: HET Index $=$ DNA release $_{\text {Stimulated }} /$ DNA release Non-stimulated. .

\section{Genotyping and SNP association analysis}

DNA was isolated from $20 \mu \mathrm{L}$ of whole blood using the Gentra Puregene Kit (Qiagen, Waltham, MA) following the manufacturer's recommended protocol for avian blood. Isolated DNA samples were treated with ribonuclease (RNase A, Qiagen). Spectrophotometric assessment of each sample was used to ensure concentration exceeded $50 \mathrm{ng} / \mu \mathrm{L}$ and $260 / 280$ ratios were checked to assess purity. Samples were submitted for genotyping of 57,636 SNPs using the chicken 60K SNP panel developed by the United States Department of Agriculture chicken Genome-Wide Marker Assisted Selection consortium and the Illumina iSelect platform protocol (DNA Landmarks, Inc., Montreal, Canada). The SNPs with a minor allele frequency below 0.05 or a genotyping call-rate frequency of less than 0.90 were removed from the analysis, leaving 12,456 SNPs in the broiler $\times$ Leghorn AIL and 
13,052 in the broiler $\times$ Fayoumi AIL for analysis. These SNPs were tested within each AIL for association with each of the heterophil functional phenotypes using PROC MIXED in SAS (SAS Institute, Cary, NC) with sex and SNP genotype as fixed effects and sampling day (which included the effect of hatch) as a random effect.

Gene set analysis

A list of all annotated genes for chicken (Gallus gallus), based on genome build 2.1, was obtained from the National Center for Biotechnology Information GenBank database. Each SNP was used as a marker for the nearest protein coding gene within $100 \mathrm{~kb}$, and a $p$ value for each gene was determined as the lowest $p$ value for any SNP within that gene. Suggestive and significant thresholds of $p<0.01$ and $p<0.001$, respectively, were set as cutoffs for identifying genes important in heterophil function. Gene sets for each heterophil phenotype were generated based on SNP genotype effects, including both suggestive and significant genes to increase the breadth of the search. Each gene set was tested for enrichment of known gene ontology (GO) functions and pathways, against a background of all genes associated with a tested SNP, using the Database for Annotation, Visualization, and Integrated Discovery (Dennis et al. 2003; Huang et al. 2009).

\section{Results}

Heterophil function of advanced intercross $(\mathrm{Br} \times \mathrm{Leg}$ and $\mathrm{Br} \times$ Fay) birds

The heterophil functional phenotypes of phagocytosis, bacterial killing, oxidative burst, and HET production were analyzed for the main effect of AIL (or "cross," Fig. 1). Genetic cross significantly affected the phagocytosis and bacterial killing phenotypes ( $p=0.0005$ and 0.0014 , respectively), with the $\mathrm{Br} \times$ Fay AIL heterophils outperforming the $\mathrm{Br} \times$ Leg AIL heterophils. Phagocytosis and killing of $S$. enteritidis bacteria were correlated $(r=0.281, p=1.0 \times$ $10^{-6}$ ); however, there were no other significant relationships between the heterophil functional phenotypes (Table 1).
Fig. 1 Heterophil functional phenotype least square means with standard error by advanced intercross line. Bars that do not share a letter are significantly different. a Heterophil phagocytosis of $S$. enteritidis was higher in the $\mathrm{Br} \times$ Fay advanced intercross line (AIL). b Killing of $S$. enteritidis was higher for $\mathrm{Br} \times$ Fay AIL heterophils. The $\mathbf{c}$ oxidative burst and $\mathbf{d}$ HET production heterophil phenotypes were not significantly affected by advanced intercross line

\section{a

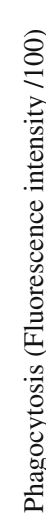

$\mathrm{n}=327, p=0.0005$

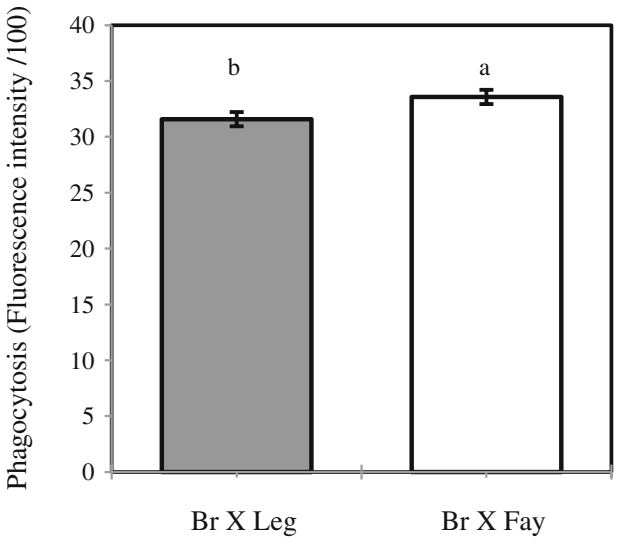

C

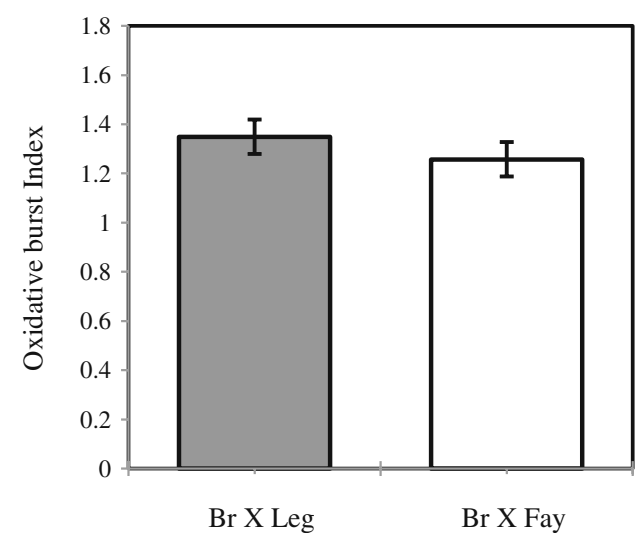

b

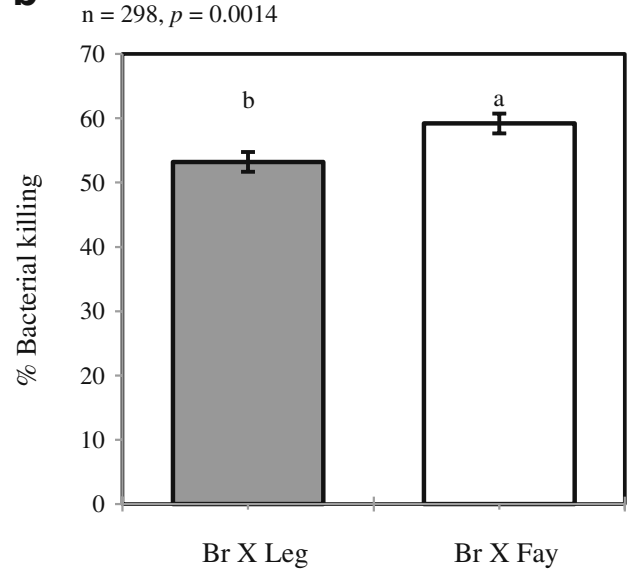

d $\mathrm{n}=308, p=0.16$

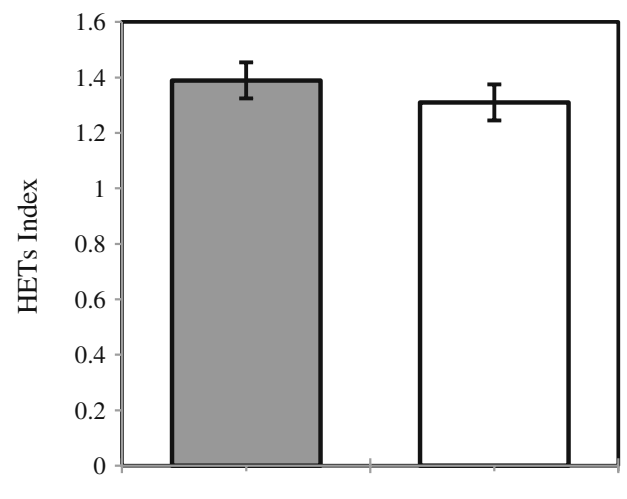


Table 1 Correlations between heterophil functional phenotypes

\begin{tabular}{|c|c|c|c|c|}
\hline & Phagocytosis & Bacterial killing & Oxidative burst & HET production \\
\hline Phagocytosis & - & $0.281(<0.001)$ & $-0.009(0.876)$ & $0.055(0.342)$ \\
\hline Bacterial killing & & - & $0.066(0.254)$ & $0.075(0.194)$ \\
\hline Oxidative burst & & & - & $-0.009(0.876)$ \\
\hline HET production & & & & - \\
\hline
\end{tabular}

Correlations are expressed as Pearson's coefficient, $r$ ( $p$ value). Phagocytosis and killing of $S$. enteritidis bacteria show a significant low positive correlation. All other heterophil phenotypes are uncorrelated

Effects of SNPs within known genes on heterophil phagocytosis and HET production

The genome-wide SNP scan generated 13,052 informative SNPs in the Br $\times$ Fay AIL and 12,456 in the $\mathrm{Br} \times$ Leg AIL, with only 1,517 SNPs segregating in both populations. Two loci previously associated with resistance to Salmonella were identified in the current study as significantly affecting heterophil function: the SAL1 locus on chromosome 5 (Fife et al. 2009) and SLC11A1 on chromosome 7 (Lamont et al. 2002). Markers on chromosome 5 associated with HET production in the $\mathrm{Br} \times$ Fay AIL with a peak $-\log$ ( $p$ value) of 3.30 at $54.063 \mathrm{Mb}$ and showed suggestive significance at $54.433 \mathrm{Mb}$ (Fig. 2a). Both of these regions overlap the 54.0 to $54.8 \mathrm{Mb}$ region harboring the SAL1 quantitative trait locus (Fife et al. 2009). Higher HET index values were associated with the heterozygous genotype (AG) at 54,063,035 bp in the Br X Fay AIL, and this genotype occurs at much higher frequency in the $\mathrm{Br} \times$ Fay AIL when compared to the $\mathrm{Br} \times \mathrm{Leg}$ AIL (Table 2). A peak $-\log$ ( $p$ value) score of 3.39 in the $\mathrm{Br} \times$ Fay AIL HET production phenotype and 3.10 in the $\mathrm{Br} \times$ Leg AIL phagocytosis phenotype coincide with the SLC11A1 locus on chromosome 7 (Fig. 2b). Higher HET index values were associated with the GG genotype at $24,100,562 \mathrm{bp}$, with similar values in both the $\mathrm{Br} \times$ Fay and $\mathrm{Br} \times$ Leg AILs, but with reduced phagocytosis only in the $\mathrm{Br} \times$ Leg AIL (Table 2). Other known genes which were strongly associated with heterophil function $(-\log (p$ value $)>3.00)$ are presented in Table 3.

Novel loci associated with heterophil phagocytosis and HET production

The region of chromosome 6 spanning from 2.24 to $2.63 \mathrm{Mb}$ was significantly associated with HET production (peak $-\log (p$ value $)=4.62$ in the $\mathrm{Br} \times$ Fay AIL $)$. This region overlaps LOC768651 in the National Center for Biotechnology Information database (Fig. 2c), a gene predicted by the eukaryotic gene prediction algorithm Gnomon and supported by expressed sequence tag evidence. It is possible that this hypothetical protein is involved in HET production or that this genomic region regulates another gene that affects the phenotype. Use of the Basic Local Alignment Search Tool to search nucleotide databases does not identify any similar genomic sequences in other species, and a cross-species search of expressed sequence tags does not reveal any non-chicken transcripts with significant similarity to the predicted gene.

Molecular pathways associated with heterophil function

Gene set enrichment analysis through the Database for Annotation, Visualization and Integrated Discovery (Dennis et al. 2003) was used to identify GO terms significantly enriched for genes affecting each heterophil functional phenotype (Table 3). In addition to GO terms associated with common immune response mechanisms, such as leukocyte activation (GO:0045321) and T-cell activation (GO:0042110), more specific processes unique to each heterophil phenotype were identified. Genes in regions associated with phagocytosis were associated with cell projection organization (GO:0030030). Bacterial killing was associated with genes involved in induction of apoptosis (GO:0006917). The heterophil oxidative burst gene set was enriched for leukocyte differentiation (GO:0002521) and transforming growth factor $\beta$ signaling (GO:0007179). Production of HETs was associated with genes whose products act in the lysosome (GO:0005764), protein catabolism (GO:0030163), and protein localization (GO:0008104).

\section{Discussion}

Association of heterophil function with known disease resistance genes

The previously mapped SAL1 locus is associated with the level of splenic bacterial colonization in chickens infected with Salmonella typhimurium. Recent fine mapping efforts isolated $S A L 1$ to the region from 54.0 to $54.8 \mathrm{Mb}$ of Gga 5, and AKT1 
Fig. 2 Genetic association of loci with heterophil extracellular trap (HET) production and phagocytosis. Curves indicate the positional $-\log (p$ value $)$ for the indicated trait. Position on each chromosome is represented in $\mathrm{Mb}$ based on genome build 2.1 (NCBI). Thresholds for suggestive and significant SNP associations are indicated at $p=0.01$ and $p=0.001$, respectively. Loci previously identified as affecting the response to $S$. enteritidis are shown as thick lines. a Genetic association of HET production with the $S A L 1$ locus on chromosome 5 . b Genetic association of HET production with the SLC11A1 locus on chromosome 7. c Genetic association of chromosome 6 with HET production at a predicted gene locus a

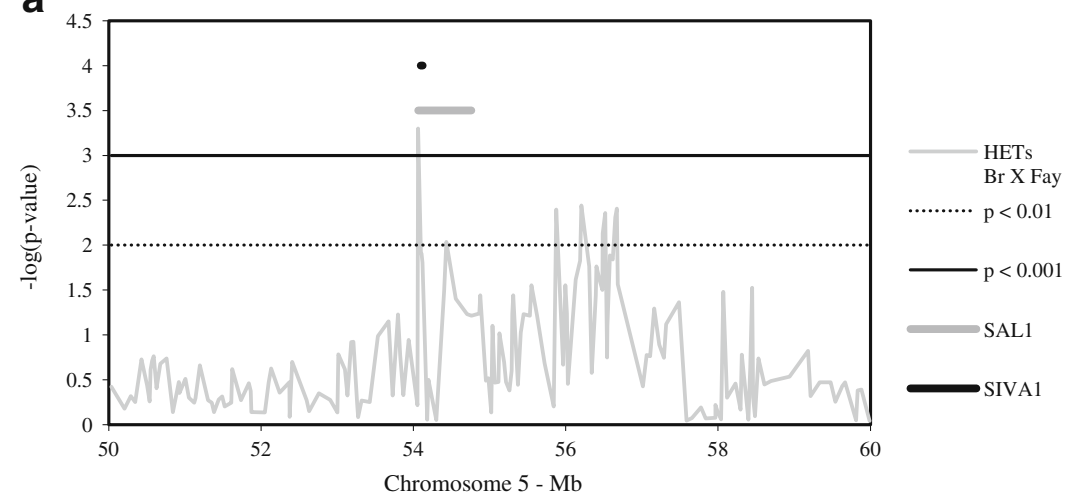

b
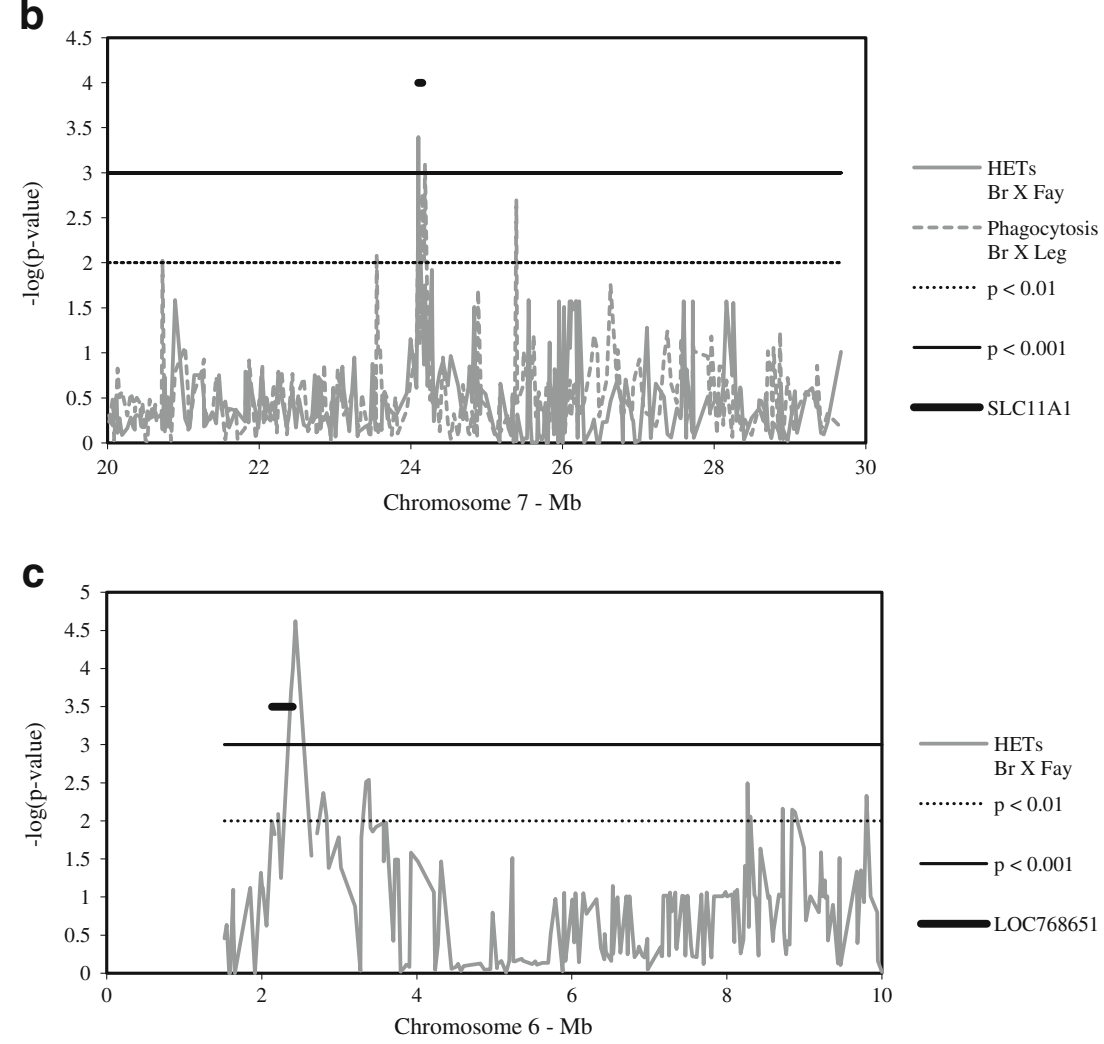

Table 2 Genotype frequencies and associations with heterophil phenotypes

\begin{tabular}{|c|c|c|c|c|c|c|c|}
\hline & & \multicolumn{3}{|c|}{ SAL1 locus } & \multicolumn{3}{|c|}{ SLC11A1 gene } \\
\hline & & $\mathrm{AA}$ & $\mathrm{AG}$ & GG & AA & $\mathrm{AG}$ & GG \\
\hline \multirow[t]{2}{*}{ (A) Genotype freq. } & $\mathrm{Br} \times$ Fay & 0.084 & 0.704 & 0.215 & 0.082 & 0.664 & 0.254 \\
\hline & $\mathrm{Br} \times \mathrm{Leg}$ & 0.005 & 0.038 & 0.957 & 0.951 & 0.022 & 0.027 \\
\hline \multirow[t]{2}{*}{ (B) HET index } & $\mathrm{Br} \times$ Fay & 0.655 & 0.864 & 0.716 & 0.810 & 0.807 & 0.935 \\
\hline & $\mathrm{Br} \times \mathrm{Leg}$ & 0.935 & 0.721 & 0.780 & 0.772 & 0.706 & 0.921 \\
\hline \multirow[t]{2}{*}{ Phagocytosis } & $\mathrm{Br} \times$ Fay & & & & 2,994 & 3,077 & 3,280 \\
\hline & $\mathrm{Br} \times \mathrm{Leg}$ & & & & 2,661 & 2,125 & 1,708 \\
\hline
\end{tabular}

(A) Genotype frequencies at the SAL1 locus and SLC11A1 gene and (B) associated effects on heterophil extracellular trap (HET) production and phagocytosis in the broiler $\times$ Leghorn $(\mathrm{Br} \times \mathrm{Leg})$ and broiler $\times$ Fayoumi $(\mathrm{Br} \times$ Fay $)$ advanced intercross lines 
Table 3 Genes and GO terms identified as over-represented in gene sets associated with heterophil function

\begin{tabular}{|c|c|c|c|c|}
\hline & \multicolumn{4}{|l|}{ Phenotype } \\
\hline & Phagocytosis & Bacterial killing & Oxidative burst & HET production \\
\hline \multirow{21}{*}{$\begin{array}{l}\text { Genes with strong } \\
\text { support }\end{array}$} & Gga 2 & Gga 3 & Gga 3 & Gga 2 \\
\hline & $A R H G A P 21$ & FOXO3 & $P P P 2 R 5 A$ & $N P C 1$ \\
\hline & ITGA8 & Gga 17 & $M A P 3 K 7$ & MYD88 \\
\hline & $T G F B R 2$ & $R A P G E F 1$ & Gga 8 & OXSRI \\
\hline & Gga 3 & Gga 24 & PRKAA2 & Gga 3 \\
\hline & $B 3 G N T 2$ & $M P Z L 3$ & Gga 13 & MAN1A1 \\
\hline & $E H B P 1$ & CXCR5 & $E B F 1$ & Gga 4 \\
\hline & $I G F 2 R$ & & & $F G F 13$ \\
\hline & $R A B 32$ & & & AF4 (AFF1) \\
\hline & TIAM2 & & & EPHA5 \\
\hline & Gga 4 & & & $S C A R B 2$ \\
\hline & $R A P 2 C$ & & & Gga 5 \\
\hline & HHIP & & & SIVA1 \\
\hline & $J A K M I P 1$ & & & $A K T 1$ \\
\hline & Gga 7 & & & Gga 7 \\
\hline & $S L C 11 A 1$ & & & SLC11A1 \\
\hline & Gga 13 & & & Gga 9 \\
\hline & $C L T B$ & & & ARMC8 \\
\hline & TIMD4 & & & \\
\hline & Gga 24 & & & \\
\hline & TIRAP & & & \\
\hline \multirow[t]{3}{*}{$\begin{array}{l}\text { Significantly enriched } \\
\text { GO terms }\end{array}$} & Leukocyte activation (0.00039) & Leukocyte activation $(0.0034)$ & TGF $\beta$ signaling $(0.0046)$ & $\begin{array}{l}\text { Protein catabolism } \\
\quad(0.0015)\end{array}$ \\
\hline & Cell projection organization $(0.0054)$ & T-cell activation $(0.025)$ & $\begin{array}{l}\text { Leukocyte differentiation } \\
\quad(0.0078)\end{array}$ & Lysosome $(0.0077)$ \\
\hline & T-cell activation $(0.0025)$ & Induction of apoptosis $(0.04)$ & & $\begin{array}{l}\text { Protein localization } \\
(0.0082)\end{array}$ \\
\hline
\end{tabular}

Genes listed as associated with each functional phenotype had SNP genotype $p$ values less than 0.001 for at least two SNPs within $100 \mathrm{~kb}$ of the gene. GO terms were identified using the functional annotation clustering tool of the Database for Annotation, Visualization and Integrated Discovery (Dennis et al. 2003). $p$ values indicated for significantly enriched GO terms were generated through DAVID functional annotation clustering

and SIVA1 have been proposed as positional candidate genes for SAL1 function (Fife et al. 2009). The results of the current study give strong support for SIVA1 as a regulator of HET production ( $p=0.0005$ in the $\mathrm{Br} \times$ Fay AIL). The overlapping genomic region regulating these two phenotypes suggests that resistance to $S$. typhimurium conferred by the $S A L 1$ locus may be due to augmented heterophil function. The frequency of the beneficial genotype at the peak $-\log (p$ value) $(\mathrm{AG})$ is significantly higher in the $\mathrm{Br} \times$ Fay AIL (0.704) than in the $\mathrm{Br}$ $\times$ Leg AIL (0.038), and the founding Leghorn line is fixed for the $G$ allele, which could contribute to reduced HET production by Leghorn heterophils.

The natural-resistance associated macrophage protein (Nramp1 or Slc11a1) is important in the immune response to intracellular pathogens (Forbes and Gros 2003) and has been associated with resistance to $S$. enteritidis colonization in chickens (Lamont et al. 2002; Beaumont et al. 2003). The SLC11A1 gene codes a membrane-bound metal ion transporter which localizes to the phagosomal membrane (Forbes and Gros 2003; Gruenheid et al. 1997). It is thought that Slc1lal activity reduces the availability of metal ions, particularly $\mathrm{Fe}^{2+}$, for sustaining bacterial populations (Forbes and Gros 2003), and that bacteria in turn can increase expression of virulence genes, particularly those involved in iron acquisition (Zaharik et al. 2002). In the current study, SNPs in the region of this gene were associated with HET production ( $p=0.0004$ in the $\mathrm{Br} \times$ Fay AIL) and phagocytosis ( $p=0.0008$ in the $\mathrm{Br} \times \operatorname{Leg}$ AIL). The association of SLC11A1 with these phenotypes suggests that it may play a larger role in the immune response 
by contributing to the leukocyte function, in addition to inhibiting bacterial survival. Although assays of SLC11A1 expression have not been reported in heterophils, the protein is present in the granules of mature human neutrophils (Cannone-Hergaux et al. 2002) and bovine neutrophils increase its expression following binding of lipopolysaccharide (Worku and Morris 2009). The founding Fayoumi line is fixed for the beneficial GG genotype at $24,100,562 \mathrm{bp}$, and this genotype is associated with increased HET production in both the $\mathrm{Br} \times$ Fay and $\mathrm{Br} \times$ Leg AILs. In the $\mathrm{Br} \times$ Leg AIL the GG genotype is associated with reduced phagocytosis, and the absence of this relationship in the $\mathrm{Br} \times$ Fay AIL suggests that there may be epistatic interactions with other loci affecting this phenotype. The association of SLC11A1 with heterophilmediated resistance adds to the body of research supporting the significance of this gene in combating pathogens, and further elucidates mechanisms of action.

Identification of a likely mechanism for extracellular trap production through cell death

Siva-1 is an apoptotic factor which acts in activation-induced cell death of T-cells (Py et al. 2004) and associates with nonreceptor tyrosine kinases c-Abl and ARG (or ABL1) in the response to reactive oxygen species (Cao et al. 2001). Binding of Siva-1 to CD27 (a member of the tumor necrosis factor receptor superfamily) inhibits the anti-apoptotic proteins Bcl--xL and Bcl-2 (Prasad et al. 1997; Xue et al. 2002). While many of the proteins which interact with Siva1 in mammals do not yet have reported orthologs in the chicken, CABL, ABLI, and PSTPIP1, a cytoskeletal adaptor, all show suggestive association with the HETs phenotype in the current analysis (six, two, and four SNPs with $p<0.01$, respectively). The association of a known apoptotic factor with the HETs phenotype is of particular interest as this supports production of extracellular traps as a cell death mechanism. The concept of "ETosis," a cell death process stimulated upon direct contact with a pathogen, has been described in neutrophils and other granulocytes (Fuchs et al. 2007; Wartha and Henriques-Normark 2008); however, the molecular pathway has not been previously elucidated. In mice, macrophage cell death mediated through caspase-1 is an effective defense against intracellular pathogens, including S. typhimurium (Miao et al. 2010). CD27mediated apoptosis initiates signaling through caspase8 and produces a similar cellular phenotype to that described in ETosis of mouse neutrophils (Fuchs et al. 2007; Py et al. 2004). A more rapid mechanism of extracellular trap production has been observed using cells in flow conditions and suggested to occur in vasculature (Clark et al. 2007), and this mechanism likely uses a different pathway.
Putative disease resistance loci that affect heterophil extracellular trap production and phagocytosis

The association of a novel locus on chromosome 6 with heterophil function suggests the presence of a gene or regulatory region important in the innate immune response. The locus on chromosome 6 associated with HET production is in a region with few identified genes and overlaps with the predicted gene LOC768651. The lack of homology to genomic or expressed sequence tag sequence from other species gives little insight into this predicted locus, and it is possible that phenotypic association with this region derives from the action of a non-protein coding region. Further study of uncharacterized and predicted loci in chickens and other species is needed to clarify what, if any, role(s) they may play in PMN function.

\section{Conclusions}

This study has identified associations of chicken heterophil function with polymorphisms at several loci, with implications for the use of genomic assisted selection to enhance immune response and our understanding of the link between heterophil function and resistance to Salmonella. The association of the relatively wellcharacterized Salmonella resistance loci SAL1 and SLC11A1 with heterophil anti-bacterial activity underlines the important role these leukocytes play in disease resistance. Our findings suggest that SAL1-conferred resistance acts through a mechanism linking PMN extracellular trap production to Siva-1/CD27-mediated cell death. The association of previously uncharacterized loci with heterophil functional phenotypes suggests that this targeted approach to studying immune response phenotypes on a cellular rather than organismal level has potential to identify genetic effects which are not detected on the larger scale. As annotation and characterization of chicken and mammalian genomes improves the use of genomic analysis to identify important functional regulators will become more powerful.

Acknowledgments The authors gratefully thank the Iowa State University Poultry Science Research and Education Center staff for bird care and past and present members of the Lamont lab group for the assistance with sample collection. The authors thank the United States Department of Agriculture chicken Genome-wide Marker Assisted Selection consortium for access to the chicken $60 \mathrm{~K}$ Illumina iSelect SNP chip. This work was supported by grants from the United States Department of Agriculture National Institute of Food and Agriculture Animal Genome program (2007-3560417866), National Needs Graduate Fellowship program (200538420-15810, SBR), and Royal Thai Government Scholarship (PC). 
Open Access This article is distributed under the terms of the Creative Commons Attribution Noncommercial License which permits any noncommercial use, distribution, and reproduction in any medium, provided the original author(s) and source are credited.

\section{References}

Beaumont C, Protais J, Pitel F, Leveque G, Malo D, Lantier F, Plisson-Petit F, Colin P, Protais M, Le Roy P, Elsen JM, Milan D, Lantier I, Neau A, Salvat G, Vignal A (2003) Effect of two candidate genes on the Salmonella carrier state in fowl. Poult Sci 82:721-726

Brune K, Leffell MS, Spitznagel JK (1972) Microbicidal activity of peroxidaseless chicken heterophil leukocytes. Infect Immun 5:283-287

Cannone-Hergaux F, Calafat J, Richer E, Cellier M, Grinstein S, Borregaard N, Gros P (2002) Expression and subcellular localization of NRAMP1 in human neutrophil granules. Blood 100:268-275

Cao C, Ren X, Kharbanda S, Koleske A, Prasad KVS, Kufe D (2001) The ARG tyrosine kinase interacts with Siva-1 in the apoptotic response to oxidative stress. J Biol Chem 276:1146511468

Cheeseman JH, Kaiser MG, Ciraci C, Kaiser P, Lamont SJ (2007) Breed effect on early cytokine mRNA expression in spleen and cecum of chickens with and without Salmonella enteritidis infection. Dev Comp Immunol 31:52-60

Chuammitri P, Ostojić J, Andreasen CB, Redmond SB, Lamont SJ, Palić D (2009) Chicken heterophil extracellular traps (HETs): novel defense mechanism of chicken heterophils. Vet Immunol Immunopathol 129:126-131

Clark SR, Ma AC, Tavener SA, McDonald B, Goodarzi Z, Kelly MM, Patel KD, Chakrabarti S, McAvoy E, Sinclair GD, Keys EM, Allen-Vercoe E, DeVinney R, Doig CJ, Green FHY, Kubes P (2007) Platelet TLR4 activates neutrophil extracellular traps to ensare bacteria in septic blood. Nat Med 13:463469

Dennis G Jr, Sherman BT, Hosack DA, Yang J, Gao W, Lane HC, Lempicki RA (2003) DAVID: Database for annotation, visualization, and integrated discovery. Genome Biol 4:R60

Farnell MB, Crippen TL, He H, Swaggerty CL, Kogut MH (2003) Oxidative burst mediated by toll like receptors (TLR) and CD14 on avian heterophils stimulated with bacterial toll agonists. Dev Comp Immunol 27:423-429

Fife MS, Salmon N, Hocking PM, Kaiser P (2009) Fine mapping of the chicken salmonellosis resistance locus (SAL1). Anim Genet 40:871-877

Fife MS, Howell JS, Salmon N, Hocking PM, van Diemen PM, Jones MA, Stevens MP, Kaiser P (2010) Genome-wide SNP analysis identifies major QTL for Salmonella colonization in the chicken. Anim Genet. doi:101111/j1365-3822052201002090x

Forbes JR, Gros P (2003) Iron, manganese, and cobalt transport by Nramp1 (Slc11a1) and Nramp2 (Slc11a2) expressed at the plasma membrane. Blood 102:1884-1892

Fuchs TA, Abed U, Goosmann C, Hurwitz R, Schulze I, Wahn V, Weinrauch Y, Brinkmann V, Zychlinsky A (2007) Novel cell death program leads to neutrophil extracellular traps. J Cell Biol 176:231-241

Gruenheid S, Pinner E, Desjardins M, Gros P (1997) Natural resistance to infection with intracellular pathogens: the Nramp1 protein is recruited to the membrane of the phagosome. J Exp Med 185:717-730
Harmon BG (1998) Avian heterophils in inflammation and disease resistance. Poult Sci 77:972-977

He H, Lowry VK, Ferro PM, Kogut MH (2005) CpGoligodeoxynucleotide-stimulated chicken heterophil degranulation is serum cofactor and cell surface receptor dependent. Dev Comp Immunol 29:255-264

Huang DW, Sherman BT, Lempicki RA (2009) Systematic and integrative analysis of large gene lists using DAVID bioinformatics resources. Nat Protoc 4:44-57

Kaiser MG, Wing T, Lamont SJ (1998) Effect of genetics, vaccine dosage, and postvaccination sampling interval on early antibody response to Salmonella enteritidis in broiler breeder chicks. Poult Sci 77:271-275

Kogut MH, Genovese KJ, Lowry VK (2001) Differential activation of signal transduction pathways mediating phagocytosis, oxidative burst, and degranulation by chicken heterophils in response to stimulation with opsonized Salmonella enteritidis. Inflammation 25(7-362): 15

Kogut MH, McGruder ED, Hargis BM, Corrier DE, DeLoach JR (1995) In vivo activation of heterophil function in chickens following injection with Salmonella enteritidis-immune lymphokines. J Leukoc Biol 57:56-62

Kogut MH, Iqbal M, He H, Philbin V, Kaiser P, Smith A (2005) Expression and function of Toll-like receptors in chicken heterophils. Dev Comp Immunol 29:791-807

Lamont SJ, Kaiser MG, Liu W (2002) Candidate genes for resistance to Salmonella enteritidis colonization in chickens as detected in a novel genetic cross. Vet Immunol Immunopathol 87:423-428

Miao EA, Leaf IA, Treuting PM, Mao DP, Dors M, Sarkar A, Warren SE, Wewers MD, Aderem A (2010) Caspase-1-induced pyroptosis is an innate immune effector mechanism against intracellular bacteria. Nat Immunol 11:1135-1142

Prasad KV, Ao Z, Yoon Y, Wu MX, Rizk M, Jacquot S, Schlossman SF (1997) CD27, a member of the tumor necrosis factor receptor family, induces apoptosis and binds to Siva, a proapoptotic protein. Proc Natl Acad Sci USA 94:6346-6351

Py B, Slomianny C, Auberger P, Petit PX, Benichou S (2004) Siva-1 and an alternative splice form lacking the death domain, Siva-2, similarly induce apoptosis in $\mathrm{T}$ lymphocytes via a caspasedependent mitochondrial pathway. J Immunol 172:4008-4017

Redmond SB, Chuammitri P, Andreasen CB, Palić D, Lamont SJ (2009) Chicken heterophils from commercially selected and non-selected genetic lines express cytokines differently after in vitro exposure to Salmonella enteritidis. Vet Immunol Immunopathol 132:129-134

Redmond SB, Tell RM, Coble D, Mueller C, Palić D, Andreasen CB, Lamont SJ (2010) Differential splenic cytokine responses to dietary immune modulation by diverse chicken lines. Poult Sci 89:1635-1641

Stabler JG, McCormick TW, Powell KC, Kogut MH (1994) Avian heterophils and monocytes: phagocytic and bactericidal activities against Salmonella enteritidis. Vet Microbiol 38:293-305

Swaggerty CL, Kogut MH, Ferro PJ, Rothwell L, Pevzner IY, Kaiser P (2004) Differential cytokine mRNA expression in heterophils isolated from Salmonella-resistant and -susceptible chickens. Immunology 113:139-148

Swaggerty CL, Pevzner IY, Kaiser P, Kogut MH (2008) Profiling proinflammatory cytokine and chemokine mRNA expression levels as a novel method for selection of increased innate immune responsiveness. Vet Immunol Immunopathol 126:35-42

Wartha F, Henriques-Normark B (2008) ETosis: a novel cell death pathway. Sci Signal 1:pe25

Worku M, Morris A (2009) Binding of different forms of lipopolysaccharide and gene expression in bovine blood neutrophils. J Dairy Sci 92:3185-3193 
Xue L, Chu F, Cheng Y, Sun X, Borthakur A, Ramarao M, Pandey P, Wu M, Schlossman SF, Prasad KV (2002) Siva-1 binds to and inhibits $\mathrm{BCL}-\mathrm{XL}$-mediated protection against UV radiationinduced apoptosis. Proc Natl Acad Sci USA 99:6925-6930

Zaharik ML, Vallance BA, Puente JL, Gros P, Finlay BB (2002) Host-pathogen interactions: host resistance factor Nramp1 up-regulates the expression of Salmonella pathogenicity island-2 virulence genes. Proc Natl Acad Sci USA 99:1570515710

Zhou H, Lamont SJ (1999) Genetic characterization of biodiversity in highly inbred chicken lines by microsatellite markers. Anim Genet 30:256-264 